\title{
Biodegradable polyester-based shape memory polymers: Concepts of (supra)molecular architecturing
}

\author{
J. Karger-Kocsis ${ }^{1,2^{*}}$, S. Kéki ${ }^{3}$ \\ ${ }^{1}$ Department of Polymer Engineering, Faculty of Mechanical Engineering, Budapest University of Technology and \\ Economics, Múegyetem rkp. 3., H-1111 Budapest, Hungary \\ ${ }^{2}$ MTA-BME Research Group for Composite Science and Technology, Müegyetem rkp. 3., H-1111 Budapest, Hungary \\ ${ }^{3}$ Department of Applied Chemistry, University of Debrecen, Egyetem tér 1, H-4032 Debrecen, Hungary
}

Received 19 December 2013; accepted in revised form 25 January 2014

\begin{abstract}
Shape memory polymers (SMPs) are capable of memorizing one or more temporary shapes and recovering to the permanent shape upon an external stimulus that is usually heat. Biodegradable polymers are an emerging family within the SMPs. This minireview delivers an overlook on actual concepts of molecular and supramolecular architectures which are followed to tailor the shape memory (SM) properties of biodegradable polyesters. Because the underlying switching mechanisms of SM actions is either related to the glass transition $\left(T_{\mathrm{g}}\right)$ or melting temperatures $\left(T_{\mathrm{m}}\right)$, the related SMPs are classified as $T_{\mathrm{g}}$ - or $T_{\mathrm{m}}$-activated ones. For fixing of the permanent shape various physical and chemical networks serve, which were also introduced and discussed. Beside of the structure developments in one-way, also those in two-way SM polyesters were considered. Adjustment of the switching temperature to that of the human body, acceleration of the shape recovery, enhancement of the recovery stress, controlled degradation, and recycling aspects were concluded as main targets for the future development of SM systems with biodegradable polyesters.
\end{abstract}

Keywords: polymer synthesis, molecular engineering, smart polymers, biopolymers, biodegradable polymers

\section{Introduction}

Shape memory (SM) biodegradable polymers (SMPs) and related composites are emerging smart materials in different applications. SMPs may adopt one (dual-shape), two (triple-shape) or several (multishape) stable temporary shapes and recover their permanent shape (or other temporary shapes in case of multi-shape versions) upon the action of an external stimulus. The external stimulus may be temperature, $\mathrm{pH}$, water, light irradiation, redox condition etc. In most cases, however, the SMPs are thermally activated. The 'switching' or transformation temperature ( $\left.T_{\text {trans }}\right)$, enabling the material to return to its permanent shape, is either linked with the glass transition $\left(T_{\mathrm{g}}\right)$ or with the melting temperature $\left(T_{\mathrm{m}}\right)$.
Thus, SMPs are often subdivided based on their switch types into $T_{\mathrm{g}}$ - or $T_{\mathrm{m}}$-based SMPs. As reversible 'switches' other mechanisms such as liquid crystallization and related transitions, supermolecular assembly/disassembly, irradiation-induced reversible network formation, formation and disruption of a percolation network, may also serve [1]. The permanent shape is guaranteed by physical or chemical network structures. The latter may be both on molecular and supramolecular levels. Linkages of these networks are termed net points. The temporary shape is created by mechanical deformation above $T_{\text {trans. }}$. In some cases the deformation temperature may be below $T_{\text {trans }}$ values (i.e. $T_{\mathrm{g}}$ - and $T_{\mathrm{m}}$-linked temperatures) [2]. The macroscopic deformation applied is translated

\footnotetext{
${ }^{*}$ Corresponding author, e-mail: karger@pt.bme.hu

(C) BME-PT
} 
to conformational changes of the molecular chains, molecular segments of the networks or macroscopic deformation of the 'switching' phase. Temporary shape is fixed by maintaining the deformation via cooling causing vitrification and crystallization in $T_{\mathrm{g}}$ and $T_{\mathrm{m}}$-based SMP variants, respectively. The deformation energy, stored by this way, is released when the material is unloaded and reheated above $T_{\text {trans. Note that }} T_{\text {trans }} \geq T_{\mathrm{g}}$ or $T_{\mathrm{m}}$. Heating induces conformational rearrangements of the molecular chains and segments of the networks, melting of the crystals formed, release the constraints on macroscopically deformed phases, respectively, through which the permanent shape is restored. All what is described above is related to one-way SMPs. This means that the external stimulus activates only the change from the temporary to the permanent shape (dual-shape variant) or from one temporary to the other one in multi-shape SMPs. There are, however, two-way SMPs featuring a reversible shape change between the permanent and temporary shapes upon external stimulus.

Many works have been dealing with different SMPs, and the related knowledge is summarized in reviews and books [3-7]. SM properties are typically quantified by the shape fixity $\left(R_{\mathrm{f}}\right)$ and shape recovery ratios $\left(R_{\mathrm{r}}\right) . R_{\mathrm{f}}$ means the extent of fixing of the externally applied deformation in the temporary shape. Its value is $100 \%$ when the applied deformation, set above $T_{\text {trans }}$, is fully kept below $T_{\text {trans }}$ in the temporary shape. $R_{\mathrm{r}}$ is the percentage of the recovery of the original shape when the material is reheated above $T_{\text {trans }} \cdot R_{\mathrm{r}}=100 \%$ when the original shape of the material is fully restored. SM properties are usually determined in cyclic (one or more) thermomechanical tests performed under stress- or strain-controlled conditions. A scheme of shape programming and recovery in a thermomechanical test is given in three-dimensional (3D) stress-deformation-temperature plot in Figure 1. Beside of $R_{\mathrm{f}}$ and $R_{\mathrm{r}}$, further SM characteristics, such as the temperature interval of recovery, recovery rate and recovery force, can be measured. An excellent overview on the quantification of SM behavior in cyclic thermomechanical tests was compiled by Sauter et al. [8].

Environmental concerns and public interest for sustainable growth fuel the research and development (R\&D) works to produce and use biodegradable and biobased polymers. Biodegradable means that the polymers decompose to carbon dioxide, water and

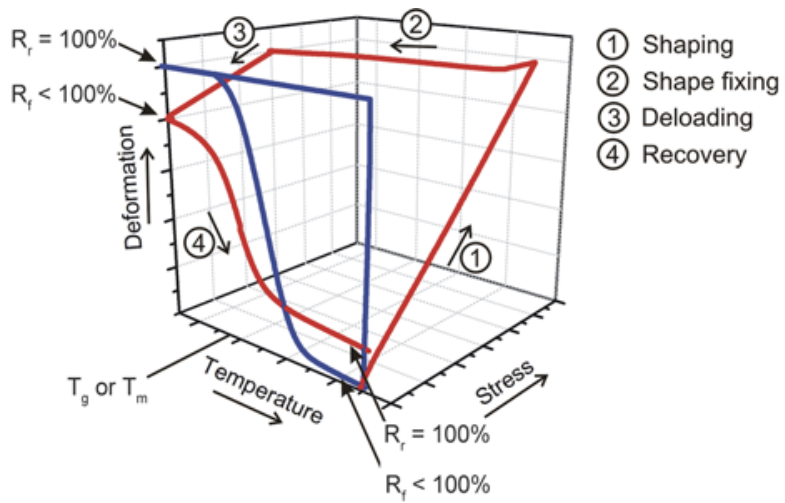

Figure 1. Single SM cycles of one-way (1W) SMPs in 3D plots, schematically. This figure also shows the reading of the $R_{\mathrm{f}}$ and $R_{\mathrm{r}}$ values

biomass under aerobic, while the decomposition products contain methane after decomposition in anaerobic conditions. Biobased polymers originate from biomass, synthesized by microorganisms or produced by biotechnological routes from monomers got from renewable resources. Biodegradable polymers can be produced from petrochemical sources, as well. Poly( $\varepsilon$-caprolactone) (PCL), polyesteramides, aliphatic- aromatic copolyesters belong to this category. Major part of biodegradable polymers are polyesters, and in particular, aliphatic polyesters. Monomers of the latter can be synthesized from renewable resources.

Biodegradable polymers, and especially polyesters, play a key role in medical applications due to their biodegradability and versatile syntheses resulting in tailored properties. SM biodegradable polyesters are predestinated for medical use because the related 'SM devices' (e.g. sutures, catheters, stents) should be present only temporarily in the human body. Their versatile synthesis is the premise of adjusting $T_{\text {trans }}$ to the temperature of the body.

Next we shall give an overview on SMP systems which are composed fully or partly from biodegradable polyesters. This overlook is aimed at introducing the basic strategies of tailoring the (supra)molecular structures to meet the required performance.

\section{One-way SMP (1W-SMP)}

It is intuitive that to control the SM properties attention should be focused on the manipulation of the switching or fixing structures, or on both. The goals behind may be different: broadening or narrowing the temperature interval of the switching transition, reduction of the switch temperature (i.e. $T_{\text {trans }}$ ), enhancing the recovery force and speed, creation of 
additional physical network, substitution of the physical network by a chemical one, generation of a temporary networks etc. Next we shall introduce the actual (supra)molecular design concepts for $T_{\mathrm{g}^{-}}$ and $T_{\mathrm{m}}$-based SM biodegradable polyesters. This survey concentrates on general strategies, which can be adapted to other SM polymer systems, rather to deliver a detailed listing of the related developments.

\subsection{Molecular structure}

\subsection{1. $\mathrm{T}_{\mathrm{g}}$-based systems}

The working principle of $T_{\mathrm{g}}$-based SMPs is depicted schematically in Figure 2. As net points, remaining unaffected during deformation, molecular entanglements and entanglements along with crystalline domains act in linear (i.e. thermoplastic) amorphous and semicrystalline systems, respectively. The net points are structural units of the above physical networks.

Semicrystalline poly(L-lactic acid) (PLLA or PLA) exhibits $T_{\mathrm{g}}$ and $T_{\mathrm{m}}$ in the ranges of 60-70 and 150$170^{\circ} \mathrm{C}$, respectively. In its uncrosslinked form the crystallites and entanglements act as net points. They can ensure, however, only moderate $R_{\mathrm{f}}$ and $R_{\mathrm{r}}$ data. Variation of the molecular weight $\left(M_{\mathrm{W}}\right)$, that affects both entanglement and crystallization, yielded limited success [9]. Incorporation of hydroxyapatite nanoparticles up to $50 \mathrm{wt} \%$ into poly(D,L-lactide) (PDLLA) resulted in improved $R_{\mathrm{r}}$. The initial $R_{\mathrm{r}}$ value of PDLLA was enhanced from ca. 80 to $98 \%$ upon filling. This was attributed to H-bonding between the matrix and nanoparticles creating net points in an additional physical network-like structure $[10,11]$. Accordingly, a more efficient network should be configured. Further, $T_{\text {trans }}$ usually higher than $T_{\mathrm{g}}$, is too high for biomedical applications and thus its reduction is essential. These two aspects are targets of the ongoing research. $T_{\mathrm{g}}$ is traditionally reduced by plasticizers. For this purpose water [12] and other plasticizers [13] were tried. To avoid the migration of the plasticizer, especially when added in high amount, it is straightforward to crosslink the PLA [13]. So, here we already see an example for the strategy to influence both the switches and net points simultaneously. This approach is quite frequent because manipulation of the switch phase is often accompanied with a change in the net points and vice verse. This change is not always wanted but appears as a necessary 'byproduct' of the design strategy followed. Just one example to underline the latter: the crystalline phase may diminish with

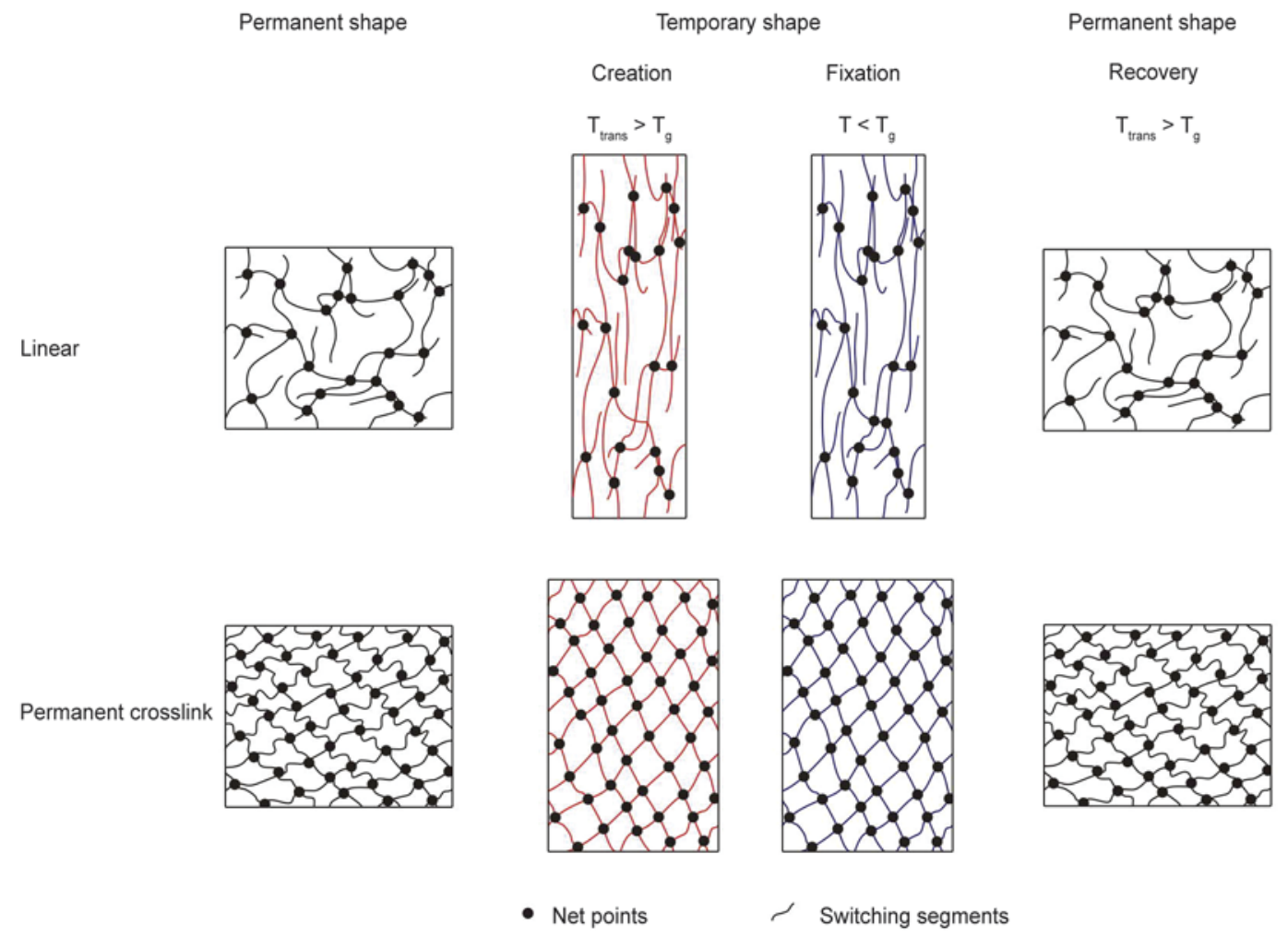

Figure 2. Molecular mechanisms of the thermally-induced 1W-SM effect in amorphous linear (thermoplastic) and crosslinked (thermoset) polymers. Note: temporary shape is created by tensile deformation 
crosslinking whereby even a $T_{\mathrm{m}}$ - based SMP can be converted in a $T_{\mathrm{g}}$-based one.

Plasticization is, however, not the best tool to manipulate $T_{\mathrm{g}}$. Plasticizer may bleed out with the time, and facilitates the cold crystallization owing to $T_{\mathrm{g}}$ reduction, as well. This substantially affects the SM properties of $T_{\mathrm{g}}$-based slow crystallizing polymers such as PLA. A far better method is to reduce the $T_{\mathrm{g}}$ is the synthesis of copolymers. Linear poly(L-lactideco- $\varepsilon$-caprolactone)s (PLACLs) were produced by Lu et al. [14]. The lactide/lactone ratio was varied between 90/10 and 60/40 which was associated with a large change in the $T_{\mathrm{g}}$ (reduction from 54 to $14^{\circ} \mathrm{C}$ ) and $T_{\mathrm{m}}$, as well. Here again $T_{\mathrm{g}}$ adjustment was accompanied with a notable change in $T_{\mathrm{m}}$. For shaping $T_{\text {trans }}=T_{\mathrm{g}}+15^{\circ} \mathrm{C}$, whereas for shape fixing $T=T_{\mathrm{g}}-15^{\circ} \mathrm{C}$ were selected. $R_{\mathrm{f}}$ decreased, whereas $R_{\mathrm{r}}$ increased with increasing caprolactone content of the copolymer. Copolymerization may work also in the other direction, i.e. toward $T_{\mathrm{g}}$ enhancement. Poly(trimethylene carbonate) (PTMC) itself is an amorphous elastomer having a $T_{\mathrm{g}} \sim-15^{\circ} \mathrm{C}$, which is very low for many SM applications. By copolymerization of TMC with D,L-lactides the $T_{\mathrm{g}}$ of the resulting copolymer (PTMC-DLLA) could be set between 11 and $44^{\circ} \mathrm{C}$. As $T_{\text {trans }}\left(=37^{\circ} \mathrm{C}\right)>T_{\mathrm{g}}\left(=22^{\circ} \mathrm{C}\right)$ was used for shaping (elongation to $150 \%$ ), and fix- ing occurred $T=0^{\circ} \mathrm{C}$ [15]. Several works were devoted to synthesize terpolymers composed of trimethylene carbonate, L-lactide and glycolide (PTMC-LLA-GA) [16].

Crosslinking is the favored way to 'stabilize' the network and its net points. Crosslinking usually brings further benefits with, such as high recovery stress and rate compared to the linear counterparts. The group of Lendlein functionalized oligomers composed of L-lactide and glycolide with UV-curable methacrylate end groups [17]. The comonomer ratio and length of the chain segments in the corresponding polymer (PLLA-GA) were varied in the experiments. The $T_{\mathrm{g}}$ values of the photocured random PLLA-GA copolymers were between $T_{\mathrm{g}}=50$ $55^{\circ} \mathrm{C}$. Instead of permanent crosslinks, introduced by various techniques (UV irradiation, high energy irradiation, peroxide), temporary ones can also be used. They may be - among others - photo- and thermoreversible ones. Diels-Alder type reactions are favored for thermoresponsive SMPs. The beauty of this approach is that the thermoreversible reaction allows us to recycle the corresponding polymer via remelting. As Diels-Alder reaction the cycloaddition, occurring between furan and maleimide groups, is preferred. This selection is due to the fact that the adduct forms and the retro Diels-Alder

Table 1. Selected concepts and their realization for $T_{\mathrm{g}}$-based SM biodegradable polyesters. Designation: - not reported

\begin{tabular}{|c|c|c|c|c|c|}
\hline \multirow{2}{*}{$\begin{array}{l}\text { Material, } \\
\text { composition }\end{array}$} & \multicolumn{2}{|c|}{ Temporary shape, 'switching' } & \multirow{2}{*}{$\begin{array}{l}\text { Permanent shape, 'fixing' } \\
\text { network, net points }\end{array}$} & \multirow[b]{2}{*}{ Concept, realization } & \multirow[b]{2}{*}{ Reference } \\
\hline & $\begin{array}{c}\mathbf{T}_{\mathrm{g}} \\
{\left[{ }^{\circ} \mathbf{C}\right]}\end{array}$ & $\begin{array}{l}\mathbf{T}_{\text {trans }} \\
{\left[{ }^{\circ} \mathbf{C}\right]}\end{array}$ & & & \\
\hline PLA (PLLA) & $62-64$ & $T_{\mathrm{g}}+15$ & $\begin{array}{l}\text { crystalline domains + entanglements } \\
\text { (physical network) }\end{array}$ & various $M_{\mathrm{W}}$ PLAs & 9 \\
\hline PLA & 49 & $<227$ & $\begin{array}{l}\text { entanglements } \\
\text { (physical network) }\end{array}$ & $\begin{array}{l}\text { simulation study: } T_{\mathrm{g}} \text { manipulation } \\
\text { by water uptake }(<2 \mathrm{wt} \%)\end{array}$ & 12 \\
\hline PLA & $\sim-50$ & - & $\begin{array}{l}\text { permanent crosslinks } \\
\text { (chemical network) }\end{array}$ & $\begin{array}{l}\text { elastic PLA gel with high amount } \\
(<40 \mathrm{wt} \%) \text { of plasticizer, cured by } \\
\text { electron beam. Swelling by } \\
\text { plasticizer after crosslinking }\end{array}$ & 13 \\
\hline PLACL & $14-54$ & $T_{\mathrm{g}}+15$ & $\begin{array}{l}\text { crystalline domains + entanglements } \\
\text { (physical network). At } 40 \mathrm{wt} \% \\
\text { caprolactone content only } \\
\text { entanglements }\end{array}$ & $\begin{array}{l}T_{\mathrm{g}} \text { reduction by copolymerization } \\
\text { that reduced } T_{\mathrm{m}}, \text { too. Copolymer at } \\
\text { high caprolactone content } \\
\text { amorphous }\end{array}$ & 14 \\
\hline $\begin{array}{l}\text { PTMC } \\
\text { PTMC-DLLA }\end{array}$ & $\begin{array}{l}\sim-15 \\
11-44\end{array}$ & $\begin{array}{c}- \\
T_{\mathrm{g}}+15 \\
\end{array}$ & $\begin{array}{l}\text { entanglements (physical network) } \\
\text { entanglements (physical network) }\end{array}$ & $\begin{array}{l}\text { not suited for SM } \\
T_{\mathrm{g}} \text { increase via copolymerization }\end{array}$ & 15 \\
\hline $\begin{array}{l}\text { PTMC-LLA- } \\
\text { GA }\end{array}$ & $38-42$ & 48 & entanglements (physical network) & $\begin{array}{l}\text { terpolymerization through } \\
\text { compositional variations }\end{array}$ & 16 \\
\hline PLLA-GA & $50-55$ & - & $\begin{array}{l}\text { permanent crosslinks by UV } \\
\text { irradiation (chemical network) }\end{array}$ & $\begin{array}{l}\text { crosslinking of oligo(L-lactide- } r \text { - } \\
\text { glycolide)dimethacrylate. Crosslink } \\
\text { density varied via the } M_{\mathrm{W}} \text { of the } \\
\text { monomers and their ratio }\end{array}$ & 17 \\
\hline PLA & $50-65$ & $60-100$ & $\begin{array}{l}\text { temporary crosslinks } \\
\text { (thermoreversible chemical network) }\end{array}$ & $\begin{array}{l}\text { furan-functionalized PLA } \\
\text { crosslinked with maleimide } \\
\text { functional 'linkers' - Diels-Alder } \\
\text { cycloaddition }\end{array}$ & 18 \\
\hline
\end{tabular}


reaction runs at rather low temperatures. Inoue et al. [18] reported that the Diels-Alder type crosslinking of properly functionalized PLA yields good SM properties. Recall that here $T_{\text {trans }}(=60$ $100^{\circ} \mathrm{C}$ ) is still linked with the $T_{\mathrm{g}}$ for PLA. The SM function was lost when the material was heated to $T \sim 160^{\circ} \mathrm{C}$ where the retro reaction, disconnecting the crosslinks, took place. The above strategies are summarized in Table 1.

\subsection{2. $T_{m}$-based systems}

In semicrystalline polymers $T_{\mathrm{m}}$ is linked with $T_{\text {trans }}$. To use the melting/recrystallization transition instead of the glass/rubbery one is beneficial since the former transition is 'sharper' (occurring in a smaller temperature range) and faster than the latter one. Similar to $T_{\mathrm{g}}$-based SMPs, chemical (covalent or thermoreversible) or physical crosslinking (through phase segregated domains), and their combinations, may be the 'net points' which guarantee the permanent shape. The molecular mechanism, underlying the SM function in $T_{\mathrm{m}}$-activated SMPs, is depicted schematically in Figure 3.

Accordingly, the polymer is heated above its $T_{\mathrm{m}}$ and deformed. The deformation induced temporary shape is fixed by cooling during which crystallizations takes place. $T_{\mathrm{m}}$ is never matched with the crystallization temperature $\left(T_{\mathrm{c}}\right)$ mostly due to the differently long molecular chains (undercooling effect). Recovery occurs after heating above $T_{\mathrm{m}}$ followed by cooling below $T_{\mathrm{c}}$. Figure 3 also highlights that the initial crystalline structure may be not be completely restored after the SM cycle. This means a reduction in the $R_{\mathrm{r}}$ value.
Unlike PLA, the ductility of PCL is very high which predestinates it for SM applications. The $T_{\mathrm{g}}$ and $T_{\mathrm{m}}$ of PCL are at about -50 and $60^{\circ} \mathrm{C}$, respectively. In order to make use of its $T_{\mathrm{m}}$ as $T_{\text {trans }}$ PCL should be crosslinked by a suitable manner. Otherwise only the chain entanglements serve as net points. On the other hand, $T_{\mathrm{m}}$ of PCL is rather high for many biomedical applications and thus its reduction is the other major goal of R\&D works.

\section{Physical networks}

A novel approach was recommended by Luo et al. [19] to 'strengthen' the physical network of PCL and thus improve its SM performance. The cited authors prepared inclusion complexes between $\alpha$ cyclodextrin and PCL. Through this host-guest complexation a peculiar physical network has been created with 'naked' PCL segments as 'switches' and cyclodextrin-PCL inclusion complex domains as additional net points. A seldom used crosslinking technique is to create ionic clusters as net points through incorporation of ionic monomers in the main chain [20]. They can be, however, easily incorporated into polyesters in polycondensation reactions. The ionic aggregates may restrict the crystallization of the main chain or its segments. Consequently, creation of ionomers may be a reasonable approach to tune $T_{8}$ of semicrystalline SMPs.

\section{Chemical networks}

Permanent crosslinks in PCL were produced by solgel chemistry [21]. The related pathway contained the alkoxysilane end grouping of an $\alpha, \omega$-hydroxyl terminated PCL, followed by hydrolysis and poly-

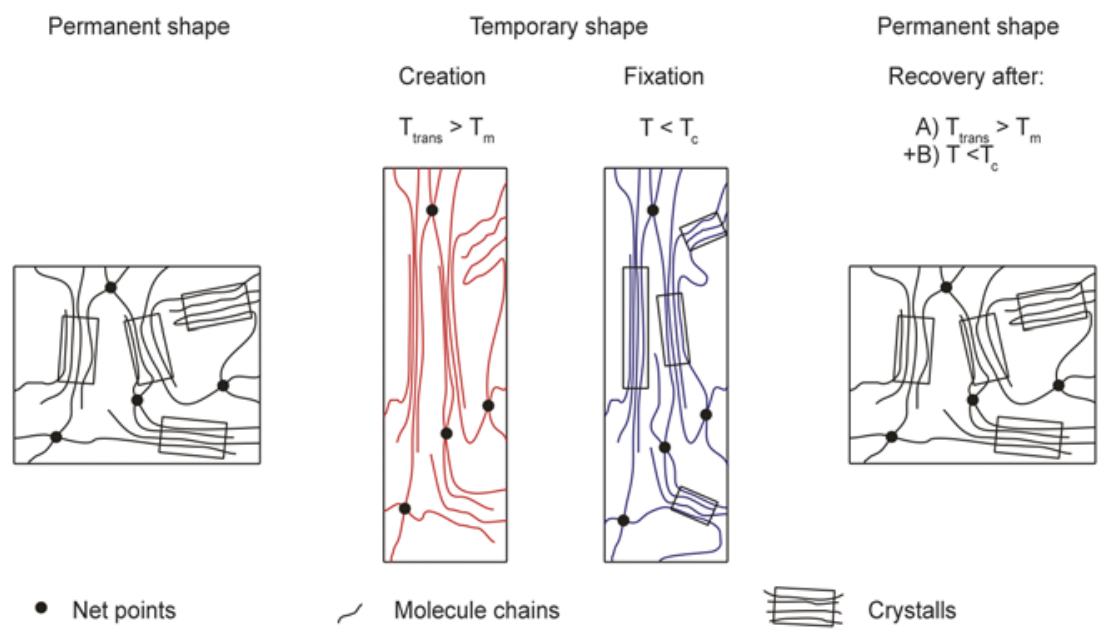

Figure 3. Molecular mechanisms of the thermally-induced SM effect in semicrystalline linear (thermoplastic) and crosslinked (thermoset) polymers. Note: temporary shape is created by tensile deformation 
condensation reactions of the terminal alkoxysilane groups. The created chemical crosslinks maintained the crystallization ability of PCL. The $T_{\mathrm{m}}$ and crystallization temperature $\left(T_{\mathrm{c}}\right)$ of PCL were, however, affected by the crosslinking degree. This is a further demonstration that manipulation of the net points may affect the switching phase (and vice versa). The resulting material showed both one- and twoway SM behaviors. In a companion paper the same authors [22] prepared peroxide crosslinked PCL with different molecular architectures. In this case the PCL was terminated by methacrylate and crosslinked in its melt phase. Polyhedral silsesquioxane (POSS) containing PCL with acrylate end groups were also synthesized and photocrosslinked. Narendra Kumar et al. [23] elaborated a synthesis route for producing thermally and magnetically activated triple-shape memory polymers using methacrylate end functionalized crystallizable PCL $\left(T_{\mathrm{m}}=55^{\circ} \mathrm{C}\right)$ and polyethylene glycol (PEG) $\left(T_{\mathrm{m}}=38^{\circ} \mathrm{C}\right)$. The copolymer was cured by peroxide in presence and absence of silica coated magnetite nanoparticles. The outcome was a magnetically active SMP. For programming of the two temporary shapes the above $T_{\mathrm{m}}$ values were considered whereby adapting one- or two-step shape programming procedures. Peroxide crosslinked poly(propylene sebacate), synthesized from biorenewable resources, exhibited a $T_{\mathrm{m}}$ at about $50^{\circ} \mathrm{C}$ serving as $T_{\text {trans }}$ in the SM cycle. The value of $T_{\mathrm{m}}$ could be tuned by the peroxide crosslinking and boehmite nanofillers content yielding a temperature interval between 37 and $51^{\circ} \mathrm{C}$, which is close to the body temperature [24]. Schmidt [25] produced thermosets from oligomeric $\varepsilon$-caprolactone dimethacrylate and butyl acrylate by peroxide crosslinking. Into the network $\mathrm{Fe}_{3} \mathrm{O}_{4}$ nanoparticles were also embedded to trigger the $\mathrm{SM}$ function by electromagnetic activation. The magnetite particles in this case worked for the 'remote' control of the temperature by transforming the electromagnetic energy to heat. $T_{\mathrm{m}}$ of the PCL segments $\left(43-49^{\circ} \mathrm{C}\right)$ was selected as $T_{\text {trans. }}$.

UV-induced crosslinking is another possibility. $\varepsilon-$ caprolactone diol oligomers can easily be converted into the related dimethacrylates which can be efficiently photocured [26]. During their SM programming $T_{\mathrm{m}}$ of the PCL segments served as $T_{\text {trans }}$. The latter could be changed between 30 and $50^{\circ} \mathrm{C}$ via the $M_{\mathrm{W}}$ of the PCL diol. The photosets showed excellent SM properties in multiple cycles. Thus,
$R_{\mathrm{f}}=86-97 \%$ and $R_{\mathrm{r}}=92-97 \%$ data were measured after the $5^{\text {th }}$ cycle. Crosslinkable functional groups may appear as end or side groups, and even in the main macromolecular chains. Garle et al. [27] modified PCL homo- and copolymers by cinnamate compound. The UV crosslinkable cinnamoyl side groups resulted in a crosslinked gel content of about $70 \mathrm{wt} \%$. SM transformation was governed by $T_{\mathrm{m}}$ of the PCL segments.

The group of Nagata incorporated UV curable moieties directly into the main chain of the related polymers [28-31]. Thus, photocurable, biodegradable multiblock SMPs were prepared by polycondensation from PCL diol, PEG and 5-cinnamoyloxyisophthalic acid [28]. The latter compounds acted as UV crosslinker without any photoinitiator. The semicrystalline photosets exhibited $T_{\mathrm{g}} \sim-60^{\circ} \mathrm{C}$, and $T_{\mathrm{m}}$ in the range of $35-47^{\circ} \mathrm{C}$. Both $R_{\mathrm{f}}$ and $R_{\mathrm{r}}$ values were reported above $90 \%$ when selecting tensile deformation between 100 and $300 \%$ and $T_{\text {trans }}=37-60^{\circ} \mathrm{C}$. A similar strategy was followed to produce photocrosslinked PCL [29] and copolymers [30] composed of $\varepsilon$-caprolactone and L-lactide whereby incorporating coumarin groups in the man chain. The coumarin compound may participate in reversible crosslinking depending on the wavelength. Multiblock copolymers were also synthesized from PCL diol and PLA diol via polycondensation with cinnamic acid compound [31]. Again, the latter was responsible for reversible photocuring that did not affect the crystallization of PCL but reduced that of PLA. Choosing $T_{\text {trans }}=40-60^{\circ} \mathrm{C}$, tensile elongations $100-500 \%$ and fixing temperature $22^{\circ} \mathrm{C}, R_{\mathrm{f}}$ and $R_{\mathrm{r}}$ data between 88 and $100 \%$ have been measured. The authors emphasized that reversible photocrosslinking may be a promising way to produce light-sensitive SMPs.

Defize and coworkers [32, 33] used the Diels-Alder reaction to create temporary crosslinks. They synthesized star-shaped PCLs with furan, anthracene and maleimide end functionalities, respectively. The resulting SMPs showed excellent $R_{\mathrm{f}}$ and $R_{\mathrm{r}}$ values, even after 4 cycles, using $T_{\mathrm{m}}$ of the PCL as $T_{\text {trans }}$ $\left(=65^{\circ} \mathrm{C}\right)$. The outstanding SM behavior was restored after recycling of the corresponding system. Note that recycling means here the onset of the retro Diels-Alder reaction running at $T \geq 105^{\circ} \mathrm{C}$. The anthracene end functionalization, instead of furan, was foreseen to influence the kinetics of the adduct formation and its temperature stability. 
Apart from peroxide (free radical-induced) and photocrosslinking, radiation crosslinking methods can also be adapted. The Zhou and coworkers [34, 35 ] used $\gamma$-irradiation to crosslink PCL is presence and absence of various sensitizers and studied the SM behavior as a function of radiation dose and dosage rate. Recovery of the related PCLs were studied at $T=56^{\circ} \mathrm{C}$. With increasing radiation dose the recovery temperature could be decreased due to a similar decrease in $T_{\mathrm{m}}$. Introduction of polyfunctional polyester acrylates proved to be suitable additives to enhance the crosslinking degree of PCL upon $\gamma$-irradiation [35].

\section{Copolymers}

Copolymerization is the most widely used technique to control $T_{\mathrm{m}}$ and also to tune the biodegradability of polymers. Biobased polyesters composed of 1,3-propandiol, sebacic acid and itaconic acid in various ratios showed excellent SM properties after crosslinking with peroxide. $T_{\text {trans }}$ could be tuned by the composition between 12 and $54^{\circ} \mathrm{C}$ [36]. Bacterial synthesis may yield semicrystalline polyhydroxyalkanoates of various compositions and various $T_{\mathrm{m}}$ data. Ishida et al. [37] have shown how a bacterial PHA, namely poly(3-hydroxyoctanoate-co-3-hydroxyundecanoate), can be crosslinked by POSS derivative making use of UV-assisted thiol-ene coupling. The thiol compounds were tetrathiol crosslinker and thiol functionalized POSS. The feasibility of Diels-Alder coupling was shown on the example of biodegradable polyester by Ninh and Bettinger [38]. In this case hyperbranched poly(glycerol-cosebacate) with pendant furan groups was coupled with bifunctional maleimide crosslinker to produce an elastomeric material. POSS moieties may serve as crosslinking sites, as well. This material is, however, owing to its composition not a $T_{\mathrm{m}^{-}}$but a $T_{\mathrm{g}^{-}}$ activated one.

'Graft' and multiblock copolymers, both in linear and crosslinked forms, may have excellent SM properties, as well. Linear, cyano functionalized polynorbornene having long PCL side chains showed good SM properties according to the report of Yang et al. [39]. This polynorbornene grafted by PCL along with the cyano groups in the main chain showed higher ductility and strength than the unmodified polynorbornene. Moreover, $T_{\mathrm{m}}$ of the phase separated PCL could be well used for $T_{\text {trans }}$ in SM tests.
There are many possibilities to tailor the properties of SMPs via their block (segmented) architecture. Polyurethane (PU)-based systems are the most widely prepared and studied SMPs. Their development started in the 1990s by Hayashi, working for Mitsubishi Heavy Industries in Nagoya, Japan [40], and they are still in the focus of both industrial and academic interests [41]. This is, in particular, due to the highly versatile PU chemistry. The reason why we are mentioning them here is that the polyols used for PU synthesis are typically biodegradable polyester-based. The interested reader might have already noticed that the $\varepsilon$-caprolactone chemistry plays an important role in the reported polyesterrelated SMPs. PCL diols are traditional building blocks of PUs. Recently $\varepsilon$-caprolactone based oligomers with various molecular architectures became platform chemicals for PU and polyester syntheses [42]. The interest behind this development is due to the complete biodegradability, low $T_{\mathrm{g}}$ and relatively low $T_{\mathrm{m}}$ of PCL. PCL-based PUs are segmented polymers with excellent SM behaviors. The reaction of diisocyanate with low $M_{\mathrm{W}}$ diol chain extenders yields the 'hard', whereas the PCL chains give the 'soft' segments. Pioneering work in this field should be credited to Kim et al. [43]. It is generally accepted that the exceptional shape memory behavior of such PUs is related to their phase segregated morphology. For thermoplastic version the hard phase is responsible for memorizing the permanent, whereas the soft one for the temporary shape and its fixing $[41,43,44]$. As a consequence, $T_{\text {trans }}$ is linked to the $T_{\mathrm{m}}$ of PCL. In crosslinked PUs, the crosslinked network guarantees the permanent shape and thus transitions related to the hard phase may also be involved in SM programming. The research on SM PUs has many similarities with that on SM polyesters. Peculiar attention was paid at the copolymer architecture. Enormous efforts have been dedicated to modify both soft and hard phases in order to improve the SM performance of both linear and crosslinked PU-based SMPs. For example, triple shape memory PU systems were produced recently by generating intermolecular H-bonds between carboxyl groups of the related PU chains and pyridine rings of cholesteryl isonicotinate mesogenic units. The SP PU itself contained PCL diol and thus one of the switch temperatures was the $T_{\mathrm{m}}$ of PCL. The other switch phase, having ca. $10^{\circ} \mathrm{C}$ higher temperature than $T_{\mathrm{m}}$ of PCL, was given by the domains 
hold together by H-bonding. The $R_{\mathrm{f}}$ and $R_{\mathrm{r}}$ data of the latter was lower than those triggered by $T_{\mathrm{m}}$ of the PCL [45]. Note that this concept falls into the category of supramolecular assembly - see later. Relevant strategies followed for $T_{\mathrm{m}}$-based SMPs are listed in Table 2.

\subsection{Supramolecular architecturing}

Supramolecular structures are scaled above molecular level. Their constituents may be highly differ- ent nano- and micronsized entities, domains. The related structures involve nanodimensional molecular 'strings' (in some interpenetrating networks (IPNs)), disperse or continuous phases in micrometer range and even processing-induced higher order structures (skin-core or multilayer structures). The SM function of the related systems is further on $T_{\mathrm{g}^{-}}$ or $T_{\mathrm{m}}$-based. Scheme of the morphology of the related SMPs is given in Figure 4. The authors have to underline here that the above definition differs

Table 2. Selected concepts and their realization for $T_{\mathrm{m}}$-based SM biodegradable polyesters. Designation: - not reported

\begin{tabular}{|c|c|c|c|c|c|}
\hline \multirow{2}{*}{$\begin{array}{l}\text { Material, } \\
\text { composition }\end{array}$} & \multicolumn{2}{|c|}{ Temporary shape, 'switching' } & \multirow{2}{*}{$\begin{array}{l}\text { Permanent shape, 'fixing' } \\
\text { network, net points }\end{array}$} & \multirow[b]{2}{*}{ Concept, realization } & \multirow[b]{2}{*}{ Reference } \\
\hline & $\begin{array}{c}\mathbf{T}_{\mathbf{m}} \\
{\left[{ }^{\circ} \mathbf{C}\right]}\end{array}$ & $\begin{array}{l}\mathbf{T}_{\text {trans }} \\
{\left[{ }^{\circ} \mathbf{C}\right]}\end{array}$ & & & \\
\hline PCL & 59 & 90 & $\begin{array}{l}\text { entanglements }+ \text { inclusion } \\
\text { complexes (physical network) }\end{array}$ & $\begin{array}{l}\text { host-guest complexation with } \\
\text { cyclodextrin in solution }\end{array}$ & 19 \\
\hline $\begin{array}{l}\text { Poly(oxyethylene- } \\
\text { block-butylene } \\
\text { adipate) }\end{array}$ & $36-42$ & 40 & $\begin{array}{l}\text { entanglements }+ \text { ionic clusters } \\
\text { (physical network) }\end{array}$ & $\begin{array}{l}\text { ionomer copolymer formation via } \\
\text { polycondensation }\end{array}$ & 20 \\
\hline PCL & $25-57$ & $T_{\mathrm{m}}+40$ & $\begin{array}{l}\text { permanent crosslinks } \\
\text { (chemical network) }\end{array}$ & $\begin{array}{l}\text { crosslinking of suitable end group } \\
\text { functionalized PCLs through sol-gel } \\
\text { chemistry and peroxide. Preparation } \\
\text { of } 1 \mathrm{~W} \text { - and 2W-SMPs }\end{array}$ & 21,22 \\
\hline PCL & $\begin{array}{l}20-40(\mathrm{PEG}) \\
>50(\mathrm{PCL})\end{array}$ & 40 and 70 & $\begin{array}{l}\text { permanent crosslinks - } \\
\text { peroxide induced } \\
\text { (chemical network) }\end{array}$ & $\begin{array}{l}\text { conetwork formation using acrylate } \\
\text { functionalized PCL and PEG. PCL } \\
\text { and PEG segments crystallizable and } \\
\text { exploited for triple-shape memory } \\
\text { function - triggered thermally and } \\
\text { magnetically }\end{array}$ & 23 \\
\hline PCL & $46-56$ & 70 & $\begin{array}{l}\text { permanent crosslinks - } \\
\text { free radical induced } \\
\text { (chemical network) }\end{array}$ & $\begin{array}{l}\text { crosslinking of oligo( } \varepsilon \text {-caprolactone) } \\
\text { dimethacrylate; magnetically } \\
\text { activated by incorporation of } \mathrm{Fe}_{3} \mathrm{O}_{4} \\
\text { nanoparticles }\end{array}$ & 25 \\
\hline PCL & $44-55$ & 70 & $\begin{array}{l}\text { permanent crosslinks - } \\
\text { UV irradiation } \\
\text { (chemical network) }\end{array}$ & $\begin{array}{l}\text { crosslinking of oligo( } \varepsilon \text {-caprolactone) } \\
\text { dimethacrylate in presence and } \\
\text { absence of photoinitiator }\end{array}$ & 26 \\
\hline PCL & $29-55$ & 60 & $\begin{array}{l}\text { permanent crosslinks by UV } \\
\text { irradiation without initiator } \\
\text { (chemical network) }\end{array}$ & $\begin{array}{l}\text { caprolactone functionalized with } \\
\text { cinnamate group; random and block } \\
\text { copolymers synthesized; } T_{\mathrm{m}} \text { tuning by } \\
M_{\mathrm{W}} \text { of the caprolactone segments built } \\
\text { in the network }\end{array}$ & 27 \\
\hline PCL, PCL-LLA & $35-47$ & $37-60$ & $\begin{array}{l}\text { permanent or temporary } \\
\text { crosslinks by UV irradiation } \\
\text { (chemical network) }\end{array}$ & $\begin{array}{l}\text { crosslinking by photosensitive groups, } \\
\text { covalently built in by } \\
\text { polycondensation }\end{array}$ & $28-31$ \\
\hline PCL & 44 & 65 & $\begin{array}{l}\text { temporary crosslinks } \\
\text { (thermoreversible chemical } \\
\text { network) }\end{array}$ & $\begin{array}{l}\text { Diels-Alder reaction of star-shape } \\
\text { PCL with furan and maleimide } \\
\text { groups, effect of retro reaction on SM } \\
\text { properties studied }\end{array}$ & 32,33 \\
\hline PCL & $55-56$ & $52-55$ & $\begin{array}{l}\text { permanent crosslinks - } \\
\gamma \text {-irradiation } \\
\text { (chemical network) }\end{array}$ & $\begin{array}{l}\text { crosslinking by high energy } \\
\text { irradiation, also in presence of } \\
\text { multifunctional sensitizer }\end{array}$ & 34,35 \\
\hline $\begin{array}{l}\text { Poly(propylene } \\
\text { sebacate) } \\
\text { copolymers }\end{array}$ & $42-54$ & $T_{\mathrm{m}}+20$ & $\begin{array}{l}\text { permanent crosslinks - } \\
\text { peroxide induced } \\
\text { (chemical network) }\end{array}$ & $\begin{array}{l}T_{\mathrm{m}} \text { depression by polycondensation } \\
\text { via varied composition }\end{array}$ & 36 \\
\hline $\begin{array}{l}\text { SM PUs of } \\
\text { different } \\
\text { compositions and } \\
\text { structures }\end{array}$ & $\begin{array}{l}\text { depends on the } \\
\text { actual } T_{\mathrm{m}} \text { of } \\
\text { the } \\
\text { crystallizing } \\
\text { segment } \\
\text { (PLA-, } \\
\text { PCL-based) }\end{array}$ & $\begin{array}{c}\text { broad range } \\
\text { above } T_{\mathrm{m}}\end{array}$ & $\begin{array}{l}\text { different physical and } \\
\text { chemical networks }\end{array}$ & $\begin{array}{l}T_{\mathrm{m}} \text { reduction via crystallization in } \\
\text { confined space, } M_{\mathrm{W}} \text { change of the } \\
\text { crystallizable diols, multiblock and } \\
\text { supramolecular architectures... }\end{array}$ & $41,43-45$ \\
\hline
\end{tabular}




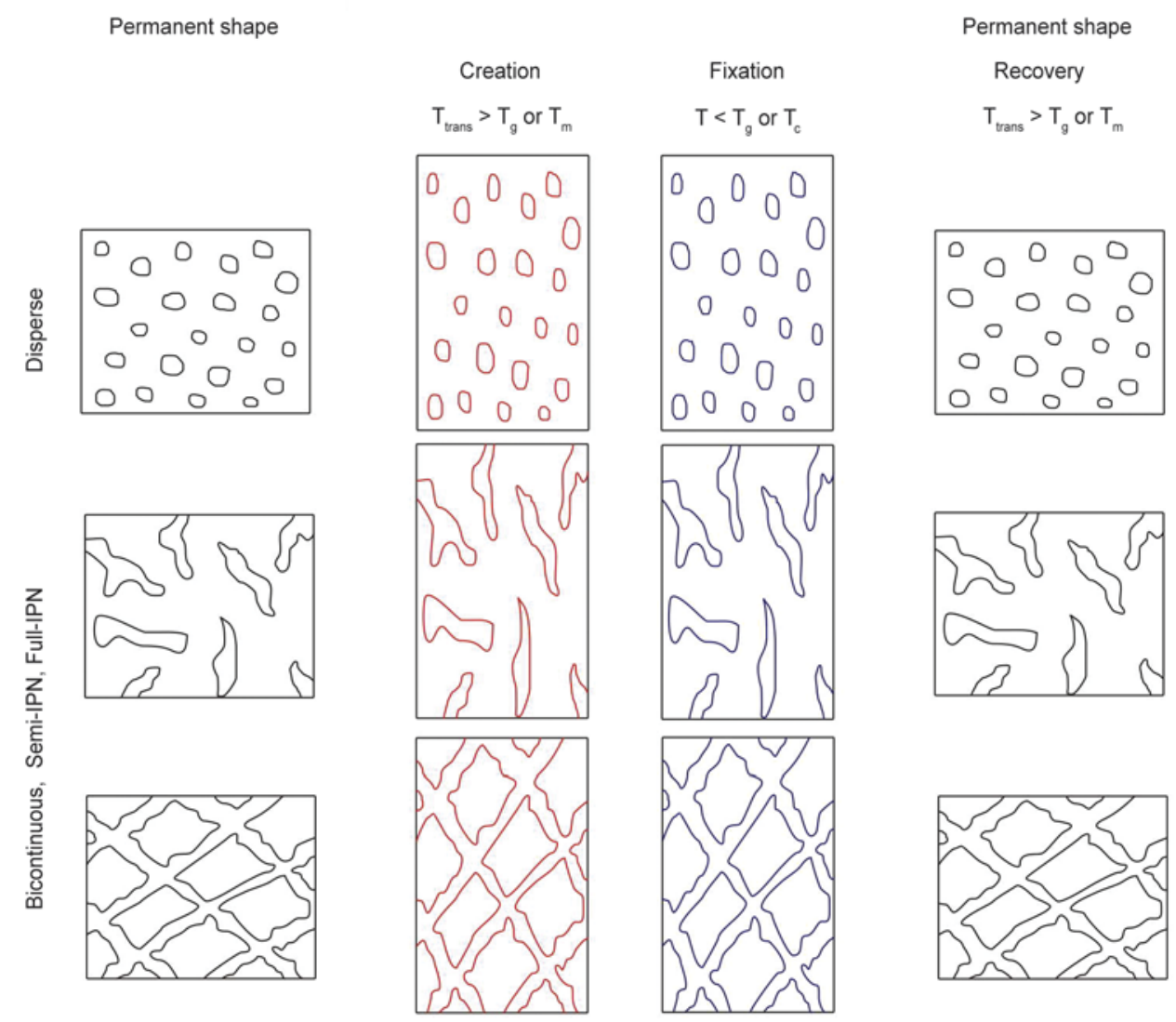

Figure 4. Scheme of the morphology changes during thermally-induced SM cycles in thermoplastic blends, semi and full IPN structures, respectively. Note: temporary shape is created by tensile deformation

from that one often used for supramolecular materials and supramolecular chemistry. Supramolecular chemistry deals with compounds with non-covalent bonds and interactions. Recall that our above classification covers a much broader range than that one of supramolecular chemistry.

\subsubsection{Blends}

Because PLA is highly brittle, it has been blended with numerous polymers to improve its toughness. A 'byproduct' of this research was the observation that some blends, in fact, showed SM feature. Lai and Lam [46] studied the SM performance of PLA/ thermoplastic PU (TPU) blends at 70/30 and 50/50 compositions. TPU was found in dispersed form at 70/30 ratio, while a bicontinuous phase structure was concluded for the PLA/PU $=50 / 50$. After deforming the specimens at $T_{\text {trans }}=25,80$ and $120^{\circ} \mathrm{C}$, the recovery was assessed in the temperature range $T=$ 20 to $160^{\circ} \mathrm{C}$. Note that the selected $T_{\text {trans }}$ data are below and above of the $T_{\mathrm{g}}$ of the PLA (ca. $80^{\circ} \mathrm{C}$ ). $R_{\mathrm{f}}, R_{\mathrm{r}}$ and the recovery stress strongly depended on $T_{\text {trans }}$ and recovery temperatures. With increasing $T_{\text {trans }} R_{\mathrm{f}}$ increased while an adverse trend was observed for $R_{\mathrm{r}}$. Zhang et al. [47] demonstrated SM behavior for PLA toughened by a polyamide-12 based elastomer, which was incorporated up to $30 \mathrm{wt} \%$. For $T_{\text {trans }}$ of the tensile loaded specimens room temperature was selected, which is in between the $T_{\mathrm{g}}$ of the polyamide elastomer $\left(T_{\mathrm{g}} \sim-50^{\circ} \mathrm{C}\right)$ and that of the PLA $\left(T_{\mathrm{g}}=75^{\circ} \mathrm{C}\right)$. Recovery was triggered at temperatures above the $T_{\mathrm{g}}$ of PLA. TPU elastomer $\left(T_{\mathrm{g}} \sim-35^{\circ} \mathrm{C}\right)$ was blended with PLA in $10 \mathrm{wt} \%$ with and without multiwall carbon nanotubes (MWCNT) after various surface treatments [48]. The latter was introduced in $10 \mathrm{wt} \%$ to achieve electroresponsive SM. For temporary shaping $T_{\mathrm{g}}$ of PLA was considered. $R_{\mathrm{r}}$ decreased with increasing number of the electroactivated thermal cycles. This was attributed to the formation of 'frozen in' crystals in the dispersed PLA phase. PLA/PCL blends in the compositions range of $100 / 0$ to $60 / 40$ were produced with and without additional MWCNT by Amirian et al. [49]. The phase segregated blends exhibited two $T_{\mathrm{g}}$ and two $T_{\mathrm{m}}$ values. The latter increased with increasing amount of MWCNT. For $T_{\text {trans }}=T_{\mathrm{g}}(\mathrm{PLA})+15^{\circ} \mathrm{C}$, while for shape fixing $T_{\mathrm{g}}(\mathrm{PLA})-15^{\circ} \mathrm{C}$ were chosen. $R_{\mathrm{r}}$ was measured at $T=70^{\circ} \mathrm{C}$ where the melting of PCL is also involved. As a consequence, both $R_{\mathrm{f}}$ and $R_{\mathrm{r}}$ decreased with 
increasing PCL content of the blends. $R_{\mathrm{f}}$ was marginally affected, while $R_{\mathrm{r}}$ went through a maximum as a function of the MWCNT content $(0-3 \mathrm{wt} \%)$ during the tensile deformation SM tests. PCL worked as efficient switching phase also in styrenic thermoplastic rubbers, such as styrene-butadiene-styrene block copolymer [50]. $R_{\mathrm{f}}$ increased steeply before leveling off above $30 \mathrm{wt} \%$ PCL content. An opposite tendency, almost a mirrored picture of the $R_{\mathrm{f}}$ course, was found for $R_{\mathrm{r}}$ as a function of the PCL content that was varied in the whole composition range. This behavior was traced to the actual morphology of the blends. As long as the thermoplastic rubber phase remained continuous excellent $R_{\mathrm{f}}$ and $R_{\mathrm{r}}$ data were measured.

Crosslinking is a useful tool to improve the SM behavior as already quoted. This technique has been adapted for PLA/PEG blends investigated in the range of 100/0 to 70/30. Crosslinking occurred by adding blocked polyisocyanate. $T_{\mathrm{g}}$ of the amorphous phase, composed of both PLA and PEG, served to select the $T_{\text {trans }}$. Both $R_{\mathrm{f}}$ and $R_{\mathrm{r}}$ increased with increasing amount of the polyisocyanate crosslinker. The crosslinking reduced also the recovery time of the corresponding blends [51].

The above treatise makes clear that acceptable SM properties can be achieved mostly by blend with bicontinuous phase structure (cf. Figure 4). The stabilization of the latter is, however, very challenging. It is the right place to mention that to distinguish between thermoset-containing semi IPN and IPN systems the term bicontinuous was used for thermoplastic blends.

\subsubsection{Processing-induced structure}

Radjabian et al. [52] used spun PLA filament, wound in helical form, for SM testing. The filament itself has a complex processing-induced supramolecular structure which does not change in the SM cycle. Thus, $R_{\mathrm{r}}$ did not change with $T_{\text {trans }}\left(70-90^{\circ} \mathrm{C}\right)$, but remained still modest $(\sim 50 \%)$. By contrast, $R_{\mathrm{f}}$ deceased with increasing $T_{\text {trans. }}$. Wang et al. [53] reinforced PLACL by in situ produced micro- and nanofibers from poly(glycolic acid) (PGA). The authors generated the PGA fibers in PLACL through in line extrusion stretching. Note that this method basically follows the microfibrillar composite concept of Fakirov ([54] and references therein). The lactide/lactone ratio of $82 / 18$ resulted in an amorphous PLACL with a $T_{\mathrm{g}}$ of $22^{\circ} \mathrm{C}$. For the temporary shape $T_{\text {trans }}=T_{\mathrm{g}}+15^{\circ} \mathrm{C}$, and for its fixing $T=$ $T_{\mathrm{g}}-15^{\circ} \mathrm{C}$ were selected. The PGA phase supported both shape fixing (restraining the molecular chain movement) and recovery (acting as additional net points).

Du et al. [55] investigated effects of layered architecture and blend morphology on the SM behavior using TPU and PCL. The TPU/PCL ratios set were $75 / 25,50 / 50$ and 25/75, respectively. The layered structure was achieved by a special multilayer coextrusion technique. The layer thickness varied with the composition ratio whereby keeping the number of layers and the overall thickness of the multilayer film as constants. $T_{\mathrm{m}}$ of PCL served as $T_{\text {trans }}$ $\left(=70^{\circ} \mathrm{C}\right)$ during shape creation that was fixed at $T=$ $21^{\circ} \mathrm{C} . R_{\mathrm{f}}$ of the multilayer film was the higher the lower its PCL content was, and it changed as a function of the thermomechanical cycles only marginally. The TPU/PCL blend at 50/50 ratio outperformed the multilayer film with respect to $R_{\mathrm{f}}$ at the same PCL content. On the other hand, all other blends showed inferior $R_{\mathrm{f}}$ data to the multilayer film.

\subsubsection{Supramolecular networks}

Combination of crosslinkable resins with linear and crosslinkable biodegradable polyesters may result in various structures. Micron-scaled dispersion of the linear polyester in a crosslinked thermoset system is the usual prerequisite of toughness improvement of the latter. The dispersion is generated by phase separation upon curing. Such systems may show SM properties though this is not yet reported for systems with biodegradable polyesters. Far more interesting are, however, those systems which feature conetwork, semi interpenetrating (semi IPN) and full IPN structures.

\section{Conetworks}

Conetworks are chemically crosslinked networks in which none of the constituents forms a continuous phase. In ideal case the conetwork is on molecular level. Its formation is, however, often accompanied with 'homocrosslinking' and the related domains are on supramolecular level. That is the reason why we are treating them here. Conetworks differ markedly from the grafted IPN structure in which both phases are continuous and chemically coupled. Li et al. [56] prepared conetwork structured thermosets by the peroxide induced copolymerization of methyl methacrylate and PCL dimethacrylate. 
The poly(methyl methacrylate)/CL ratio was varied between $80 / 20$ and $20 / 80$. The related systems exhibited a single $T_{\mathrm{g}}$ that changed as a function of composition in a broad range $\left(T_{\mathrm{g}}=110 \ldots-20^{\circ} \mathrm{C}\right)$. The broad $T_{\mathrm{g}}$ relaxation may be used to memorize multiple shapes via careful programming. The authors showed that the related conetwork may show quadruple SM, i.e. 'remembering' to three temporary shapes. The prerequisite for that is that the energy stored in the partitioned $T_{\mathrm{g}}$ range during temporary shaping should be sufficient enough for shape fixing during cooling. Erden and Jana [57] modified SM PU with polybenzoxazine. The precured benzoxazine with its phenolic hydroxyl groups can react with the polyisocyanate whereby forming a conetwork with the polyurethane. Polybenzoxazine appeared in the PU matrix in phase segregated nanoscale domains. They can be treated as net points of a second fixing phase in addition to the hard segments of the PU. Cocrosslinking with benzoxazine shifted the $T_{\mathrm{g}}$ of the corresponding systems toward higher temperatures. At the same time the recovery stress was doubled compared to that of the reference PU. Enhancing the recovery stress is a very actual research direction to meet the demand of sensors and actuators.

Epoxy (EP)-PCL conetworks were produced by Lützen et al. [58]. Crystalline PCL domains, overtaking the role of 'switch' phase, were covalently integrated into the cationically polymerized EP network. The EP/PCL ratio has been varied between $85 / 15$ and $60 / 40$. After deformation at $T_{\text {trans }}=70^{\circ} \mathrm{C}$ and fixing at $T=20^{\circ} \mathrm{C}, R_{\mathrm{f}}$ of $100 \%$ was measured.

\section{Semi interpenetrating networks (semi IPNs)}

Unlike conetworks, semi IPNs are composed of two continuous phases from which one is of thermoplastic nature. It is intuitive that the related entangled structure should contribute to the onset of SM properties. This was confirmed recently [59]. It is worth noting that entangling of the phases in semi and full IPN structures is never on molecular level though the materials may feature one single $T_{\mathrm{g}}[60]$. 'Full' IPN denotes that both constituent continuous phases are crosslinked polymers. Semi IPNs may not only have SM, but also self healing properties. Though the term 'shape memory assisted self healing' was coined by the Rodriguez et al. [61], the concept should be credited to Karger-Kocsis as quoted by Yuan et al. [62].
The group of Rodriguez et al. [61] produced semi IPNs containing high $M_{\mathrm{W}}$ PCL as thermoplastic and tetrathiol crosslinked low $M_{\mathrm{W}}$ PCL diacrylate as thermoset phase. The linear/network PCL ratio was studied between $0 / 100$ and $80 / 20$. At $200 \%$ tensile deformation $R_{\mathrm{f}}$ increased slightly, whereas $R_{\mathrm{r}}$ decreased sharply with increasing amount of the thermoplastic PCL. Self healing was demonstrated on partially broken double edge notched tensile loaded specimens making use of the essential work of fracture protocol [63]. Healing happened by wetting, diffusion and randomization of the linear PCL component above its $T_{\mathrm{m}}$, viz at $T=80^{\circ} \mathrm{C}$.

Quasi semi IPN structure can be produced by other ways. Such a structure is given when electrospun PCL nanofiber mat is infiltrated by EP followed by curing of the latter. This material showed triple shape behavior. For setting the two temporary shapes $T_{\mathrm{m}}$ of PCL and $T_{\mathrm{g}}$ of EP served. $T_{\mathrm{g}}$ of EP was below the $T_{\mathrm{m}}$ of PCL [64]. Fejös et al. [65] not only confirmed this concept on the same material combination but compared the SM behavior with that of a 'real' semi IPN structured EP/PCL at the same composition (cf. Figure 5). The latter was generated in one-pot synthesis via phase segregation. The storage modulus vs temperature traces of the PCL nanoweb containing EP and semi IPN structured EP/PCL were similar (cf. Figure 6). The dynamic mechanical analysis (DMA) traces clearly show that both EP systems have a bicontinuous phase structure because their storage moduli do not drop at the $T_{\mathrm{g}}$ of EP which would happen for PCL dispersed in the EP matrix. Instead of that, the moduli

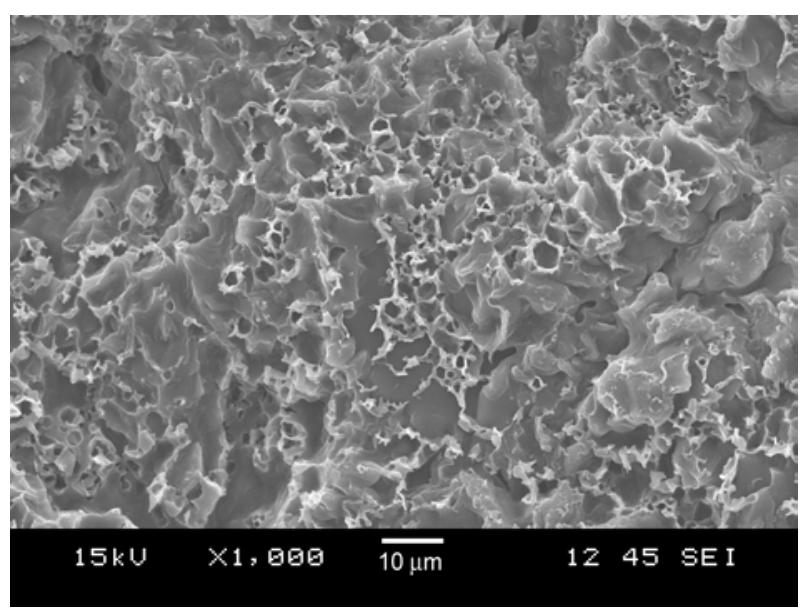

Figure 5. Etched (with methylene chloride) fracture surface of EP/PCL (=77/23 wt\%) displaying a semi IPN structure. Note: the lacy structure is due to the partially removed PCL phase 


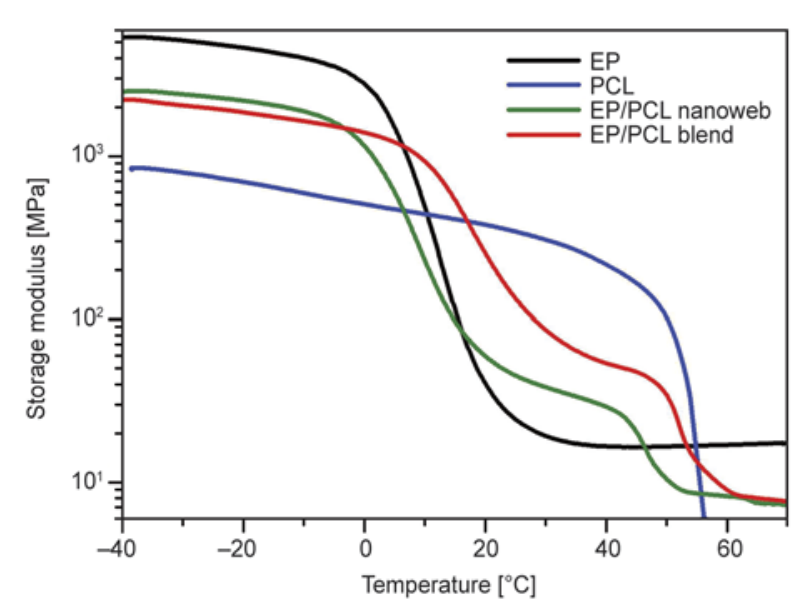

Figure 6. DMA traces (storage modulus vs temperature) of the EP with electrospun PCL nanoweb, semi IPN structured EP/PCL and the constituting PCL and EP. Notes: the PCL content in the EP/PCL combinations was $23 \mathrm{wt} \%$.

run in between those of the PCL and EP. The SM properties of the EP/PCL with semi IPN structure were somewhat better than that with the electrospun PCL nanofiber mat. Note that the above semi IPN version should have self healing activity, which was, however, not yet tested.

\section{Interpenetrating networks (IPNs)}

Full IPN structured thermosets are also suitable SMP systems. It was shown by Zhang et al. [66]. The IPN structure was composed of crosslinked PU (PLGA-based diol crosslinked by polyisocyanate) and crosslinked PEG dimethacrylate (cured by UV irradiation). The content of the latter was varied between 0 and $50 \mathrm{wt} \%$. The IPNs were amorphous and exhibited a rather broad $T_{\mathrm{g}}$ range $\left(T_{\mathrm{g}}\right.$ between -23 and $63^{\circ} \mathrm{C}$ ) that served for selection of $T_{\text {trans. }}$. Both $R_{\mathrm{f}}$ and $R_{\mathrm{r}}$ data were reported over $93 \%$. Kanazawa and Kawano filed a patent on electron beam crosslinked PLA/polystyrene having semi IPN or full IPN structures [67].

\section{Two-way SMP (2W-SMP)}

The $2 \mathrm{~W}$ effect in bulk SMPs is linked with the presence of a reversible melting/crystallization switching segment. Accordingly, for 2W-SMPs $T_{\text {trans }}=T_{\mathrm{m}}$. This is, however, only a necessary but not sufficient prerequisite. 2W-SMPs exhibit two distinct features compared to $1 \mathrm{~W}-\mathrm{SMPs}$. First, the shape change occurs between two temporary ones. Second, to trigger the reversible shape change a certain stress should be steadily maintained. The preoriented chain seg-

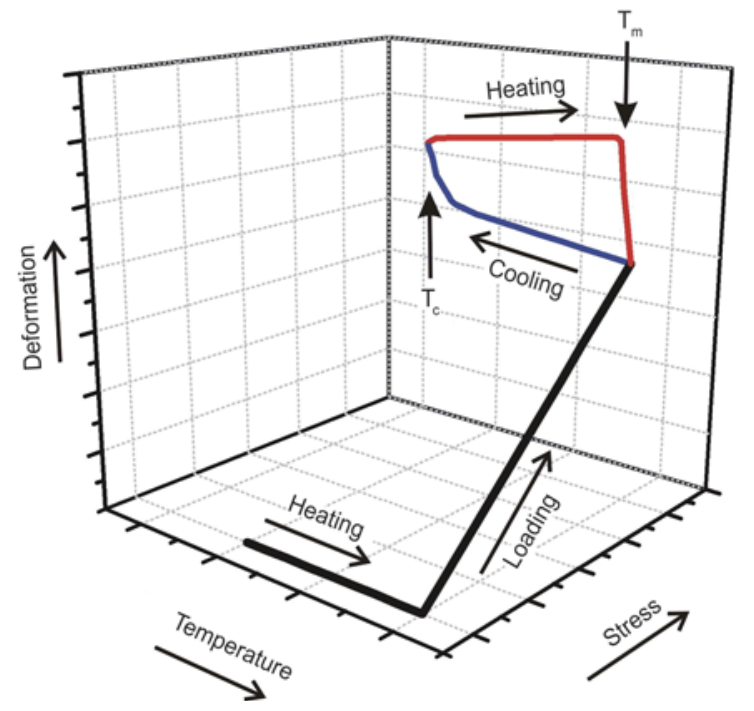

Figure 7. Single and multiple SM cycles of 2W-SMPs in 3D plots, schematically. Note that reversible shape change occurs between two temporary shapes whereby maintaining the stress.

ments crystallize upon cooling. This extends the specimen due to the crystallization heat released. Upon heating, the crystallites melt and the material contracts, shrinks. It is obvious that in order to meet the requirement, viz to return in the initial temporary shape during heating, the related structure should be crosslinked. In a linear system namely viscous flow would occur excluding the SM function. This, $2 \mathrm{~W}$-SMPs possess crosslinked (co)networks. During their design the network deformability should be adjusted to the deformation (in this case stress)-induced crystallization capability of the switch segments. This means that the $M_{\mathrm{W}}$ of the switching phase should be higher than that of the mean $M_{\mathrm{W}}$ between crosslinks. The SM cycle of a 2W-SMP is given in Figure 7. PCL-based 2W-SMPs were already produced and tested by Pandini and coworkers [21, 22].

Recently, another strategy was proposed to produce 2W-SM polymers. Behl et al. [68] suggested that creation of a special molecular conetwork (skeleton) containing reversible crystallizing/melting segments can overtake the job of external stress. Important prerequisites of this strategy are: presence of nanoscaled crystalline domains which are kept aligned by the skeleton network (thereby overtaking the role of external loading) and a broad melting range of the related crystallites. In the reversible shape change, i.e. extension upon cooling and contraction upon heating, only a given population of these crystals takes part. The concept has been 
proven also for a conetwork composed of crystalline PCL (exhibiting a very broad melting range) and poly(n-butyl acrylate) having the necessary elasticity.

\section{Conclusions}

Biodegradable polyester-based SMPs are mostly used in and developed for applications in the human body (surgical sutures, catheters and stents). That is the reason why many $R \& D$ works addressed the adjustment of $T_{\text {trans, }}$, related to $T_{\mathrm{m}}$ or $T_{\mathrm{g}}$, respectively, to the body temperature. The other aspect, usually covered in the related research, is the biodegradability. Note that the SM characteristics are markedly reduced with the degradation time. This was shown on example of PCL-based systems degraded in vitro [69]. $T_{\text {trans }}$ adjustment to body temperature and controlled biodegradability will remain preferred research topics further on [70]. Research on the SM behavior of bacterially synthesized aliphatic polyesters will be intensified.

There are, however, some general trends with SMPs. Nowadays considerable research efforts are undertaken to produce $1 \mathrm{~W}$ multi-shape and $2 \mathrm{~W}$-SMP systems. Besides, ensuring multi-functionality (such as shape memory combined with self healing) become an emerging issue. Instead of direct thermal, many works are in progress to trigger the SM function by indirect heating via electric and magnetic fields. For this purpose suitable inorganic nanofillers are incorporated. The possibility of remote actuation will be extended for the SM performance of nanostructures such as electrospun nanofiber structures [71]. Chemically-induced SM functions, especially those triggered by water swelling and dissolution, will be investigated. SM hybrid composites will become under spot of interest [72]. Apart from experimental works, modeling and simulation studies will be increasingly performed. From the viewpoint of (supra)molecular design the following tendencies can be predicted:

Linear SMPs: creation of additional physical crosslinks through host-guest complexation and ionic clustering. For their realization researcher will adapt achievements from other fields, for example for ionic clustering the works on solid electrolytes may show the right directions [73]. Further attempts will be made to stabilize the bicontinuous structures of blends by adding nanofillers, polymeric coupling agents and even by selective crosslinking. Note that the latter means a transition toward semi IPN.

Crosslinked SMPs: conetworks, semi and full IPNs will become under spot of interest. They offer many benefits, such as enhanced recovery stress, broad $T_{\mathrm{g}}$ range, multiple $T_{\mathrm{g}}$ relaxations or $T_{\mathrm{m}}$ values (important for multi-shape programming). The non-polyester compounds in these crosslinked networks will be derived from renewable resources. So, petrobased EP will be replaced by epoxy functionalized plant oils [74]. Exploring various reversible crosslinking mechanisms, known under the heading of 'click chemistry', seems to be a very promising route.

\section{Acknowledgements}

The work reported here was supported by the Hungarian Research Fund (OTKA NK 83421) and by the TÁMOP4.2.2.A-11/1/KONV-2012-0036 project co-financed by the European Union and the European Social Fund. This work was also supported by the European Union and the State of Hungary, co-financed by the European Social Fund, in the framework of TÁMOP-4.2.4.A/2-11/1-2012-0001 'National Excellence Program' (S. K.). The authors thank M. Fejös for her help in preparation of the artwork.

\section{References}

[1] Hu J., Zhu Y., Huang H., Lu J.: Recent advances in shape-memory polymers: Structure, mechanism, functionality, modeling and applications. Progress in Polymer Science, 37, 1720-1763 (2012). DOI: $10.1016 /$ j.progpolymsci.2012.06.001

[2] Sun L., Huang W. M., Wang C. C., Zhao Y., Ding Z., Purnawali H.: Optimization of the shape memory effect in shape memory polymers. Journal of Polymer Science Part A: Polymer Chemistry, 49, 3574-3581 (2011). DOI: 10.1002/pola.24794

[3] Behl M., Razzaq M. Y., Lendlein A.: Multifunctional shape-memory polymers. Advanced Materials, 22, 3388-3410 (2010). DOI: $10.1002 /$ adma.200904447

[4] Mather P. T., Luo X., Rousseau I. A.: Shape memory polymer research. Annual Review of Materials Research, 39, 445-471 (2009).

DOI: 10.1146/annurev-matsci-082908-145419

[5] Xie T.: Recent advances in polymer shape memory. Polymer, 52, 4985-5000 (2011). DOI: $10.1016 /$ j.polymer.2011.08.003

[6] Huang W. M., Zhao Y., Wang C. C., Ding Z., Purnawali H., Tang C., Zhang J. L.: Thermo/chemo-responsive shape memory effect in polymers: a sketch of working mechanisms, fundamentals and optimization. Journal of Polymer Research, 19, 9952/1-9952/34 (2012).

DOI: $10.1007 / \mathrm{s} 10965-012-9952-\mathrm{Z}$ 
[7] Lendlein A.: Shape-memory polymers. Advances in Polymer Science. (ed. Lendlein A.) Springer, Berlin, Vol 226 (2010).

[8] Sauter T., Heuchel M., Kratz K., Lendlein A.: Quantifying the shape-memory effect of polymers by cyclic thermomechanical tests. Polymer Reviews, 53, 6-40 (2013).

DOI: $10.1080 / 15583724.2012 .756519$

[9] Lu X. L., Cai W., Gao Z., Tang W. J.: Shape memory effects of poly(L-lactide) and its copolymer with poly (ع-caprolactone). Polymer Bulletin, 58, 381-391 (2007). DOI: $10.1007 / \mathrm{s} 00289-006-0680-6$

[10] Zheng X., Zhou S., Li X., Weng J.: Shape memory properties of poly(D,L-lactide)/hydroxyapatite composites. Biomaterials, 27, 4288-4295 (2006).

DOI: $10.1016 /$ j.biomaterials.2006.03.043

[11] Zhou S., Zheng X., Yu X., Wang J., Weng J., Li X., Feng B., Yin M.: Hydrogen bonding interaction of poly(D,Llactide)/hydroxyapatite nanocomposites. Chemistry of Materials, 19, 247-253 (2007).

DOI: $10.1021 / \mathrm{cm} 0619398$

[12] Ghobadi E., Heuchel M., Kratz K., Lendlein A.: Influence of the addition of water to amorphous switching domains on the simulated shape-memory properties of poly(L-lactide). Polymer, 54, 4204-4211 (2013).

DOI: $10.1016 /$ j.polymer.2013.05.064

[13] Kanazawa S.: Development of elastic polylactic acid material using electron beam radiation. SEI Technical Review: Sumitomo Electric, 66, 50-54 (2008).

[14] Lu X. L., Cai W., Gao Z. Y.: Shape-memory behaviors of biodegradable poly(L-lactide-co- $\varepsilon$-caprolactone) copolymers. Journal of Applied Polymer Science, 108, 1109-1115 (2008).

DOI: $10.1002 / a p p .27703$

[15] Yang J., Liu F., Yang L., Li S.: Hydrolytic and enzymatic degradation of poly(trimethylene carbonate- $\mathrm{co}$ D,L-lactide) random copolymers with shape memory behavior. European Polymer Journal, 46, 783-791 (2010).

DOI: 10.1016/j.eurpolymj.2009.12.017

[16] Zini E., Scandola M.: Shape memory behavior of novel (L-lactide-glycolide-trimethylene carbonate) terpolymers. Biomacromolecules, 8, 3661-3667 (2007). DOI: $10.1021 / \mathrm{bm} 700773 \mathrm{~s}$

[17] Bertmer M., Buda A., Blomenkamp-Höfges I., Kelch S., Lendlein A.: Biodegradable shape-memory polymer networks: Characterization with solid-state NMR. Macromolecules, 38, 3793-3799 (2005).

DOI: $10.1021 / \mathrm{ma} 0501489$

[18] Inoue K., Yamashiro M., Iji M.: Recyclable shapememory polymer: Poly(lactic acid) crosslinked by a thermoreversible Diels-Alder reaction. Journal of Applied Polymer Science, 112, 876-885 (2009). DOI: 10.1002/app.29469

[19] Luo H., Liu Y., Yu Z., Zhang S., Li B.: Novel biodegradable shape memory material based on partial inclusion complex formation between $\alpha$-cyclodextrin and poly( $\varepsilon$-caprolactone). Biomacromolecules, 9, 25732577 (2008).

DOI: $10.1021 / \mathrm{bm} 8004726$
[20] Han S-I., Gu B. H., Nam K. H., Im S. J., Kim S. C., Im S. S.: Novel copolyester-based ionomer for a shapememory biodegradable material. Polymer, 48, 18301834 (2007). DOI: 10.1016/j.polymer.2007.02.040

[21] Pandini S., Baldi F., Paderni K., Messori M., Toselli M., Pilati F., Gianoncelli A., Brisotto M., Bontempi E., Riccò T.: One-way and two-way shape memory behaviour of semi-crystalline networks based on sol-gel cross-linked poly( $\varepsilon$-caprolactone). Polymer, 54, 42534265 (2013).

DOI: 10.1016/j.polymer.2013.06.016

[22] Pandini S., Passera S., Messori M., Paderni K., Toselli M., Gianoncelli A., Bontempi E., Riccò T.: Two-way reversible shape memory behaviour of crosslinked poly(e-caprolactone). Polymer, 53, 1915-1924 (2012). DOI: 10.1016/j.polymer.2012.02.053

[23] Kumar U. N., Kratz K., Behl M., Lendlein A.: Shapememory properties of magnetically active triple-shape nanocomposites based on a grafted polymer network with two crystallizable switching segments. Express Polymer Letters, 6, 26-40 (2012).

DOI: $10.3144 /$ expresspolymlett.2012.4

[24] Guo W., Kang H., Chen Y., Guo B., Zhang L.: Stronger and faster degradable biobased poly(propylene sebacate) as shape memory polymer by incorporating boehmite nanoplatelets. ACS Applied Materials and Interfaces, 4, 4006-4014 (2012).

DOI: $10.1021 / \mathrm{am} 300828 \mathrm{u}$

[25] Schmidt A. M.: Electromagnetic activation of shape memory polymer networks containing magnetic nanoparticles. Macromolecular Rapid Communications, 27, 1168-1172 (2006).

DOI: $10.1002 /$ marc. 200600225

[26] Lendlein A., Schmidt A. M., Schroeter M., Langer R.: Shape-memory polymer networks from oligo(e-caprolactone)dimethacrylates. Journal of Polymer Science Part A: Polymer Chemistry, 43, 1369-1381 (2005). DOI: $10.1002 /$ pola.20598

[27] Garle A., Kong S., Ojha U., Budhlall B. M.: Thermoresponsive semicrystalline poly( $\varepsilon$-caprolactone) networks: Exploiting cross-linking with cinnamoyl moieties to design polymers with tunable shape memory. ACS Applied Materials and Interfaces, 4, 645-657 (2012). DOI: $10.1021 / \mathrm{am} 2011542$

[28] Nagata M., Inaki K.: Biodegradable and photocurable multiblock copolymers with shape-memory properties from poly( $\varepsilon$-caprolactone) diol, poly(ethylene glycol), and 5-cinnamoyloxyisophthalic acid. Journal of Applied Polymer Science, 120, 3556-3564 (2011). DOI: 10.1002/app.33531

[29] Nagata M., Yamamoto Y.: Synthesis and characterization of photocrosslinked poly( $\varepsilon$-caprolactone)s showing shape-memory properties. Journal of Polymer Science Part A: Polymer Chemistry, 47, 2422-2433 (2009). DOI: $10.1002 /$ pola.23333 
[30] Nagata M., Yamamoto Y.: Photocurable shape-memory copolymers of $\varepsilon$-caprolactone and L-lactide. Macromolecular Chemistry and Physics, 211, 1826-1835 (2010). DOI: $10.1002 / \mathrm{macp} .201000106$

[31] Nagata M., Sato Y.: Synthesis and properties of photocurable biodegradable multiblock copolymers based on poly( $\varepsilon$-caprolactone) and poly(L-lactide) segments. Journal of Polymer Science Part A: Polymer Chemistry, 43, 2426-2439 (2005).

DOI: $10.1002 /$ pola.20718

[32] Defize T., Riva R., Raquez J-M., Dubois P., Jérôme C., Alexandre M.: Thermoreversibly crosslinked poly $(\varepsilon-$ caprolactone) as recyclable shape-memory polymer network. Macromolecular Rapid Communications, 32, 1264-1269 (2011).

DOI: $10.1002 /$ marc. 201100250

[33] Defize T., Riva R., Jérôme C., Alexandre M.: Multifunctional multifunctional poly( $\varepsilon$-caprolactone)-forming networks by Diels-Alder cycloaddition: Effect of the adduct on the shape-memory properties. Macromolecular Chemistry and Physics, 213, 187-197 (2012). DOI: $10.1002 /$ macp. 201100408

[34] Zhu G., Liang G., Xu Q., Yu Q.: Shape-memory effects of radiation crosslinked poly( $\varepsilon$-caprolactone). Journal of Applied Polymer Science, 90, 1589-1595 (2003).

DOI: 10.1002/app.12736

[35] Zhu G. M., Xu Q. Y., Liang G. Z., Zhou H. F.: Shapememory behaviors of sensitizing radiation-crosslinked polycaprolactone with polyfunctional poly(ester acrylate). Journal of Applied Polymer Science, 95, 634-639 (2005).

DOI: 10.1002/app.20989

[36] Guo B., Chen Y., Lei Y., Zhang L., Zhou W. Y., Rabie A. B. M., Zhao J.: Biobased poly(propylene sebacate) as shape memory polymer with tunable switching temperature for potential biomedical applications. Biomacromolecules, 12, 1312-1321 (2011).

DOI: $10.1021 / \mathrm{bm} 2000378$

[37] Ishida K., Hortensius R., Luo X., Mather P. T.: Soft bacterial polyester-based shape memory nanocomposites featuring reconfigurable nanostructure. Journal of Polymer Science Part B: Polymer Physics, 50, 387393 (2012).

DOI: $10.1002 /$ polb.23021

[38] Ninh C., Bettinger C. J.: Reconfigurable biodegradable shape-memory elastomers via Diels-Alder coupling. Biomacromolecules, 14, 2162-2170 (2013). DOI: $10.1021 / \mathrm{bm} 4002602$

[39] Yang D., Huang W., Yu J., Jiang J., Zhang L., Xie M.: A novel shape memory polynorbornene functionalized with poly( $\varepsilon$-caprolactone) side chain and cyano group through ring-opening metathesis polymerization. Polymer, 51, 5100-5106 (2010).

DOI: $10.1016 /$ j.polymer.2010.09.009

[40] Tobushi H., Hayashi S., Kojima S.: Mechanical properties of shape memory polymer of polyurethane series. JSME International Journal Series I, 35, 296-302 (1992).
[41] Huang W. M., Yang B., Fu Y. Q.: Polyurethane shape memory polymers. CRC Press, Boca Raton (2012).

[42] Sisson A. L., Ekinci D., Lendlein A.: The contemporary role of $\varepsilon$-caprolactone chemistry to create advanced polymer architectures. Polymer, 54, 4333-4350 (2013). DOI: $10.1016 /$ j.polymer.2013.04.045

[43] Kim B. K., Lee S. Y., Xu M.: Polyurethanes having shape memory effects. Polymer, 37, 5781-5793 (1996). DOI: 10.1016/s0032-3861(96)00442-9

[44] Ping P., Wang W., Chen X., Jing X.: The influence of hard-segments on two-phase structure and shape memory properties of PCL-based segmented polyurethanes. Journal of Polymer Science Part B: Polymer Physics, 45, 557-570 (2007).

DOI: $10.1002 /$ polb.20974

[45] Chen H., Liu Y., Gong T., Wang L., Zhao K., Zhou S.: Use of intermolecular hydrogen bonding to synthesize triple-shape memory supermolecular composites. RSC Advances, 3, 7048-7056 (2013).

DOI: $10.1039 / \mathrm{c} 3 \mathrm{ra} 00091 \mathrm{e}$

[46] Lai S-M., Lan Y-C.: Shape memory properties of meltblended polylactic acid (PLA)/thermoplastic polyurethane (TPU) bio-based blends. Journal of Polymer Research, 20, 140-148 (2013).

DOI: $10.1007 / \mathrm{s} 10965-013-0140-6$

[47] Zhang W., Chen L., Zhang Y.: Surprising shape-memory effect of polylactide resulted from toughening by polyamide elastomer. Polymer, 50, 1311-1315 (2009). DOI: $10.1016 /$ j.polymer.2009.01.032

[48] Raja M., Ryu S. H., Shanmugharaj A. M.: Thermal, mechanical and electroactive shape memory properties of polyurethane (PU)/poly (lactic acid) (PLA)/CNT nanocomposites. European Polymer Journal, 49, 34923500 (2013).

DOI: $10.1016 /$ j.eurpolymj.2013.08.009

[49] Amirian M., Cai W., Chakoli A. N., Sui J., Feng J.: Shape memory properties of poly(L-lactide)/poly $(\varepsilon-$ caprolactone) blends and their composites with carbon nanotubes. Journal of Materials Science and Engineering, 4, 27-34 (2010).

[50] Zhang H., Wang H., Zhong W., Du Q.: A novel type of shape memory polymer blend and the shape memory mechanism. Polymer, 50, 1596-1601 (2009).

DOI: 10.1016/j.polymer.2009.01.011

[51] Shen T., Lu M., Zhou D., Liang L.: Influence of blocked polyisocyanate on thermomechanical, shape memory and biodegradable properties of poly(lactic acid)/poly(ethylene glycol) blends. Iranian Polymer Journal, 21, 317-323 (2012).

DOI: $10.1007 / \mathrm{s} 13726-012-0031-4$

[52] Radjabian M., Kish M. H., Mohammadi N.: Structureproperty relationship for poly(lactic acid) (PLA) filaments: Physical, thermomechanical and shape memory characterization. Journal of Polymer Research, 19, 9870/1-9870/10 (2012). DOI: $10.1007 / \mathrm{s} 10965-012-9870-0$ 
[53] Wang L-S., Chen H-C., Xiong Z-C., Pang X-B., Xiong C-D.: A completely biodegradable poly[(L-lactide)co-(E-caprolactone)] elastomer reinforced by in situ poly(glycolic acid) fibrillation: Manufacturing and shape-memory effects. Macromolecular Materials and Engineering, 295, 381-385 (2010).

DOI: $10.1002 /$ mame.200900251

[54] Bhattacharyya D., Fakirov S.: Synthetic polymer-polymer composites. Hanser, Munich (2012).

[55] Du J., Armstrong S. R., Baer E.: Co-extruded multilayer shape memory materials: Comparing layered and blend architectures. Polymer, 54, 5399-5407 (2013). DOI: $10.1016 /$ j.polymer.2013.07.012

[56] Li J., Liu T., Pan Y., Xia S., Zheng Z., Ding X., Peng Y.: A versatile polymer co-network with broadened glass transition showing adjustable multiple-shape memory effect. Macromolecular Chemistry and Physics, 213, 2246-2252 (2012).

DOI: $10.1002 /$ macp. 201200231

[57] Erden N., Jana S. C.: Synthesis and characterization of shape-memory polyurethane-polybenzoxazine compounds. Macromolecular Chemistry and Physics, 214, 1225-1237 (2013).

DOI: $10.1002 /$ macp.201200315

[58] Lützen H., Gesing T. M., Kim B. K., Hartwig A.: Novel cationically polymerized epoxy/poly( $\varepsilon$-caprolactone) polymers showing a shape memory effect. Polymer, 53, 6089-6095 (2012).

DOI: $10.1016 /$ j.polymer.2012.10.033

[59] Ratna D., Karger-Kocsis J.: Shape memory polymer system of semi-interpenetrating network structure composed of crosslinked poly (methyl methacrylate) and poly(ethylene oxide). Polymer, 52, 1063-1070 (2011). DOI: $10.1016 /$ j.polymer.2010.12.054

[60] Grishchuk S., Bonyár A., Elsäßer J., Wolynski A., Karger-Kocsis J., Wetzel B.: Toward reliable morphology assessment of thermosets via physical etching: Vinyl ester resin as an example. Express Polymer Letters, 7, 407-415 (2013).

DOI: 10.3144/expresspolymlett.2013.38

[61] Rodriguez E. D., Luo X., Mather P. T.: Linear/network poly( $\varepsilon$-caprolactone) blends exhibiting shape memory assisted self-healing (SMASH). ACS Applied Materials and Interfaces, 3, 152-161 (2011).

DOI: $10.1021 / \mathrm{am} 101012 \mathrm{c}$

[62] Yuan Y. C., Yin T., Rong M. Z., Zhang M. Q.: Self healing in polymers and polymer composites. Concepts, realization and outlook: A review. Express Polymer Letters, 2, 238-250 (2008).

DOI: $10.3144 /$ expresspolymlett.2008.29

[63] Bárány T., Czigány T., Karger-Kocsis J.: Application of the essential work of fracture (EWF) concept for polymers, related blends and composites: A review. Progress in Polymer Science, 35, 1257-1287 (2010). DOI: $10.1016 /$ j.progpolymsci.2010.07.001
[64] Luo X., Mather P. T.: Triple-shape polymeric composites (TSPCs). Advanced Functional Materials, 20, 26492656 (2010).

DOI: $10.1002 / \mathrm{adfm} .201000052$

[65] Fejős M., Molnár K., Karger-Kocsis J.: Epoxy/polycaprolactone systems with triple-shape memory effect: Electrospun nanoweb with and without graphene versus co-continuous morphology. Materials, 6, 44894504 (2013).

DOI: $10.3390 / \mathrm{ma} 6104489$

[66] Zhang S., Feng Y., Zhang L., Sun J., Xu X., Xu Y.: Novel interpenetrating networks with shape-memory properties. Journal of Polymer Science Part A: Polymer Chemistry, 45, 768-775 (2007).

DOI: $10.1002 /$ pola.21832

[67] Kanazawa S., Kawano K.: Method for producing crosslinked molded article of polylactic acid, and crosslinked molded article of polylactic acid. JP 2007182484, Japan (2007).

[68] Behl M., Kratz K., Noechel U., Sauter T., Lendlein A.: Temperature-memory polymer actuators. Proceedings of the National Academy of Sciences of the United States of America, 110, 12555-12559 (2014). DOI: $10.1073 /$ pnas.1301895110

[69] Yu X., Zhou S., Zheng X., Xiao Y., Guo T.: Influence of in vitro degradation of a biodegradable nanocomposite on its shape memory effect. The Journal of Physical Chemistry C, 113, 17630-17635 (2009).

DOI: $10.1021 / j p 9022986$

[70] Díaz-Celorio E., Franco L., Puiggalí J.: Influence of microstructure on the crystallization of segmented copolymers constituted by glycolide and trimethylene carbonate units. Express Polymer Letters, 7, 186-198 (2013).

DOI: $10.3144 /$ expresspolymlett.2013.17

[71] Gong T., Li W., Chen H., Wang L., Shao S., Zhou S.: Remotely actuated shape memory effect of electrospun composite nanofibers. Acta Biomaterialia, 8, 12481259 (2012).

DOI: $10.1016 /$ j.actbio.2011.12.006

[72] Sun L., Huang W. M., Ding Z., Zhao Y., Wang C. C., Purnawali H., Tang C.: Stimulus-responsive shape memory materials: A review. Materials and Design, 33, 577-640 (2012).

DOI: $10.1016 /$ j.matdes.2011.04.065

[73] Sownthari K., Suthanthiraray S. A.: Synthesis and characterization of an electrolyte system based on a biodegradable polymer. Express Polymer Letters, 7, 495-504 (2013).

DOI: 10.3144 /expresspolymlett.2013.46

[74] Wang R., Schuman T. P.: Vegetable oil-derived epoxy monomers and polymer blends: A comparative study with review. Express Polymer Letters, 7, 272-292 (2013).

DOI: $10.3144 /$ expresspolymlett.2013.25 